\title{
The Decline of the U.S. Rust Belt: A Macroeconomic Analysis
}

$\begin{array}{ccc}\text { Simeon Alder } & \text { David Lagakos } & \text { Lee Ohanian } \\ \text { Notre Dame } & \text { ASU } & \text { UCLA }\end{array}$

February 15, 2012

VERY PRELIMINARY AND INCOMPLETE

\begin{abstract}
Some regions of the United States fared much worse than others since the end of WWII. In this paper we document that those regions faring worst in terms of wage and employment growth from 1950-2000 tended to be those in which workers earned the largest wage premiums in 1950. We use this evidence to develop a theory of the decline of the "Rust Belt" region, which was highly unionized and paid workers substantially more than other workers of similar skill levels. We develop our theory in a two-region, open-economy version of the Neoclassical Growth model, which we parameterize to match key features of regional and aggregate data. We then use the model to ask how much differently the Rust Belt would have fared if its labor market had not been as distorted.
\end{abstract}

Keywords: Rust Belt, competition, productivity, structural change

JEL codes: E24, E65, J3, J5, L16, R13

Email: simeon.alder.1@nd.edu, lagakos@asu.edu,ohanian@econ.ucla.edu. We thank Glenn Farley for excellent research assistance. Preliminary and Incomplete - comments welcome! All potential errors are our own. 


\section{Introduction}

Some regions of the United States fared much worse than others since the end of WWII. In this paper we document a new fact about relative performance of U.S. regions. We document that regions with the lowest relative wage and employment growth from 1950-2000 tended to be those in which workers earned the largest wage premiums in 1950s. We use this evidence to develop a theory of the decline of the "Rust Belt" region, which was highly unionized and paid workers substantially more than other workers of similar skill levels. We argue that these wage premiums represent the result of noncompetitive labor (and output) markets in Rust Belt regions, and this lack of competition was a central reason behind its subsequent decline.

Our empirical work draws on census micro data from 1950 to 2000, with a $1 \%$ sample of U.S. individuals available to us once each decade. For each Metropolitan Statistical Area (MSA) in the United States, and each year, we construct measures of employment, average wages, average years of schooling and average (potential) experience of workers, among other things. We then use these variables to construct measures of the wage premium earned by workers in each MSA in each year. We define the wage premium measure as the ratio of average hourly wages in the region relative to the wage predicted by a standard Mincer regression.

When correlating the wage premiums in 1950 with subsequent growth in wages in employment from 1950 to 2000, we find strong negative correlations between both sets of variables. That is, regions with the highest wage premiums in 1950 tended to have the lowest relative growth in wages and employment from 1950 to 2000. To the best of our knowledge, we are the first to document these patterns.

We then use these facts to motivate a theory of the decline of the Rust Belt. We formalize the theory in a two-region, open-economy version of the Neoclassical Growth model. In the model, one region, which we call the "Sun Belt" for expositional purposes, is competitive and standard. The other, the Rust Belt, has a monopolistic producer and union who pick employment and price to maximize their rents. We parameterize to match key features of regional and aggregate data from 1950 to 2000, including the size of the wage premiums paid to workers in the Rust Belt region. We then use the model to ask how differently the Rust Belt would have fared had it faced more competitive pressure.

Our paper relates to the literature on competition and productivity. ${ }^{1}$ Parente and Prescott (1999) and Herrendorf and Teixeira (2012) argue that monopoly rights can reduce productivity, since incumbent monopolists face reduced incentives to innovate. Our work is perhaps most related to that of Schmitz (2005), who provides evidence from the U.S. iron ore industry that productivity

\footnotetext{
${ }^{1}$ For a recent overview of this large literature, see Holmes and Schmitz (2010).
} 
was kept low until an increase in competitive pressure in the early 1980s induced more efficient work practices. ${ }^{2}$ A common theme in our two papers is that competition reduced rents to firm owners and labor unions and forced them to improve productivity.

Our work differs from other previous analyses of the Rust Belt, which have generally treated the Rust Belt as a region receiving a bad shock relative to other regions, and have asked how it responded to the bad shock (e.g. Blanchard and Katz (1992)). In contrast, we attempt to study the root causes of the Rust Belt's poor relative performance since 1950. To our knowledge, we are the first to provide a general equilibrium analysis of the decline of the Rust Belt.

\section{Empirical Findings}

In this section we describe our empirical finding that regions with the worst relative performance in income and employment growth were those that the highest wage premiums in 1950.

\subsection{Census Micro Data}

We begin with the description of our data used for our calculations. Our basic data source is the United States Censuses of 1950 - 2000. For each year, we draw on a $1 \%$ sample of individuals using data made available from the International Public Use Microdata Series (IPUMS) ${ }^{3}$. The data allow us to compute, among other things, the age and education level of every individual in the sample, plus labor earnings and hours worked for all employed individuals. We also know the industry of employment all workers, whether or not they are self employed. Finally, we know where each individual resides. The unit of geography which we employ throughout the paper is the Metropolitan Statistical Area (MSA), which corresponds roughly to a city plus its surrounding suburbs.

In the calculations that follow, we aggregate the individual level data in one of two ways. First, by MSA, to study patterns of employment and income differences across regions of the United States and across regions over time. One limitation of our analysis of MSAs is that, for confidentiality reasons, the data only allow us to generalize about regions that are sufficiently large. ${ }^{4}$ The second way we aggregate the data is by industry, where industries are defined according to the Census's industry classifications, which have been standardized across years by IPUMS. One limitation of these industry level data is that matching them to other types of industries, such as those classified by SIC codes, will require a bridge between industries, which we discuss further below.

\footnotetext{
${ }^{2}$ Bridgman (2011) rationalizes how a firm and union may adopt inefficient work rules in the absence of competition if the union has preferences over employment levels in addition to wage levels.

${ }^{3}$ The data is publicly available from the IPUMS website: http://www.ipums.org/.

${ }^{4}$ The cutoffs differ across years, but roughly we are restricted to MSAs with greater than 100,000 persons.
} 


\subsection{Income and Employment Growth Across Regions: 1950-2000}

We now present some basic facts about income and employment growth from 1950 to 2000 in the cross-section of MSAs. To summarize, the data show that there has been large variation across regions in employment and income growth.

Table 1: Wage and Employment Growth Across MSAs: 1950-2000

\begin{tabular}{l|cc|cc}
\hline \hline & \multicolumn{2}{|c}{ Annualized Growth (\%) } & \multicolumn{2}{c}{ Cumulative Growth (\%) } \\
Measure & Wage & Employment & Wage & Employment \\
\hline 5th Percentile & 1.2 & -0.7 & 80 & -28 \\
25th Percentile & 1.4 & 0.5 & 98 & 27 \\
Median & 1.6 & 1.0 & 118 & 65 \\
Mean & 1.6 & 1.2 & 120 & 123 \\
75th Percentile & 1.7 & 1.8 & 137 & 148 \\
95th Percentile & 2.0 & 3.5 & 172 & 482 \\
\hline United States & 1.6 & 1.6 & 127 & 126 \\
\hline \hline
\end{tabular}

The unit of observation is a Metropolitan Statistical Area (MSA). The mean, median and percentiles are calculated across all MSAs with a population of at least 100,000, and are weighted by population. Employment is all private sector employees, and wage is the real average hourly wage of all wage employees in the private sector.

Table 1 presents percentiles of the distribution of wage growth and employment growth by MSA in the United States. We included all MSAs for which aggregates can be constructed in both 1950 and 2000. The first two columns of data show growth rates of wages and employment at annualized rates. For wages, the average and median MSA grew at a rate of $1.6 \%$ per year, while the growth rates ranged from a 5 th percentile of $1.2 \%$ to and 95 th percentile of $2.0 \%$. For employment, the average MSA grew at $1.2 \%$ per year, the median grew at $1.0 \%$ and the United States as a whole grew at $1.6 \%$ per year. The range on employment growth is even larger than the range for wage growth, with the 5 th percentile MSA losing $0.7 \%$ per year, and the 95 th percentile growing at $3.5 \%$ per year.

Since these differences may appear modest at annualized rates, the third and fourth columns of data present statistics of the cumulative growth from 1950 to 2000. The average MSA had wage growth of $120 \%$ and employment growth of $123 \%$, and the United States as a whole was similar at $127 \%$ and $126 \%$. The range of cumulative wage growth runs from $80 \%$ to $172 \%$ in the 5 th and 9 th percentiles, while the range of cumulative employment growth runs from $-28 \%$ to $482 \%$. Clearly there has been large variation across regions in both wage and employment growth, with relatively 
more variation in employment growth.

To put some color behind these numbers, consider which MSAs had the lowest wage growth. Of those in the bottom 5\% of wage growth, the most populated five MSAs are Pittsburgh, PA; Youngstown-Warren, Dayton, and Toledo, OH; and Flint, MI. All five of these had relatively low employment growth as well. The common theme in these MSAs is that they are midwestern cities with large manufacturing sectors in the 1950s, who had large subsequent declines in manufacturing activity. These regions are at the heart of the U.S. region known as the "Rust Belt."

At the other end of the spectrum, with wage growth in the top 5\% of all MSAs, the most populated five MSAs were Boston, MA, San Jose, CA, Austin, TX, Raleigh-Durham, NC, and Nashville, TN. Of the top 5\% of MSAs in terms of employment growth, the most populated were Atlanta, GA, Phoenix, AZ, Tampa, FL, Houston, TX and San Diego, CA. Many of these cities have been referred to as being part of the "Sun Belt" (in e.g. Blanchard and Katz (1992)). One common theme of these regions is that none of them had large manufacturing sectors in 1950, and none of them are located in the midwest.

\subsection{Measure of Wage Premiums}

What lead some regions to perform so much more poorly than others since 1950 ? We now define a variable which think may help answer this question. The variable is a proxy for the average wage premium earned by workers in each region, and is defined as follows. Let $W_{i}$ be the average hourly wage in region $i$, and let $S_{i}$ be the average "skill" of workers in $i$, defined as

$$
S_{i}=\exp \left(\alpha \cdot \text { schooling }_{i}+\beta \cdot \text { exper }_{i}+\gamma \cdot \text { exper }_{i}^{2}\right)
$$

where schooling $i$ represents the average years of schooling completed by workers in region $i$, exper $_{i}$ represents the average potential experience by workers in region $i$, and $\alpha, \beta$ and $\gamma$ represent the standard Mincer coefficients: the returns to a year of schooling, potential experience, and potential experience squared. ${ }^{5}$ Intuitively, $S_{i}$ represents the value of the schooling and experience of workers in region $i$ if they were valued at the average return to these characteristics.

The wage premium of region $i$ is then defined as

$$
P_{i}=\frac{W_{i} / S_{i}}{W_{U S} / S_{U S}}
$$

where $W_{U S}$ and $S_{U S}$ represent the U.S. average hourly wage and skill level. The wage premium $P_{i}$ represents the wage per unit of skill relative to the U.S. average. A value of $P_{i}=1.1$ for example

\footnotetext{
${ }^{5}$ We define exper $_{i}=$ age $_{i}-$ schooling $_{i}-6$ following the literature.
} 
means that works in region $i$ tend to earn $10 \%$ more per hour than other U.S. workers with the same years of schooling and experience. A value of $P_{i}=0.9$ means that workers in $i$ earn $10 \%$ less than other similar workers, and so forth.

To make (1) and (2) operational, we measure the average years of schooling and age for all private sector wage workers in each region $i$. We exclude the self employed because their reported income in the data may not be reliable, and exclude government so as to focus on market determined changes in employment and wages. For estimates of $\alpha, \beta$ and $\gamma$ we use the estimates of Bils and Klenow (2000), which are standard in the literature on Mincer returns. These estimates are 0.093, 0.032 , and -0.00048 , respectively. We then compute (1) and (2) in each region in each year from 1950 to 2000.

\subsection{Wage Premiums and Income Growth, 1950-2000}

We now turn to our first new finding, which is that cities that experienced the lowest wage growth from 1950 to 2000 tended to have the highest wage premiums in 1950. Figure 1 shows the wage premium in 1950 plotted against the (annualized) wage change from 1950 to 2000. The correlation is -0.59 , and has a p-value well below $1 \%$. Interestingly, all the regions with premiums above 1.20 below average wage growth, while all those with wage premiums below 0.8 had substantially above average wage growth.

Who were these regions on either end of the spectrum? The highest wage premiums were Detroit, MI, Terre Haute, IN, Youngstown-Warren, OH, South Bend, IN, Chicago-Gary-Lake, IL, and Flint, MI. All of these cities are commonly thought of as being part of the Rust Belt. The lowest were Waco and Austin, TX, Montgomery, AL, Columbus, GA, and Tampa, FL, all of which are been considered part of the Sun Belt.

\subsection{Wage Premiums and Employment Growth, 1950-2000}

We next turn to the relationship between the wage premiums and employment growth. Figure 2 plots the premiums in 1950 against the annualized change in employment from 1950 to 2000. As in Figure 1 , the correlation is strongly negative, at -0.38 , and again has a p-value well below $1 \%$. The culprits at either end of the spectrum are virtually identical as before, with Detroit, Terre Haute, South Bend, Warren and Flint bringing up the rear, and sun belters Orlando, Raleigh-Durham, Phoenix, Austin, Tampa and Greensboro, NC having the highest growth. 


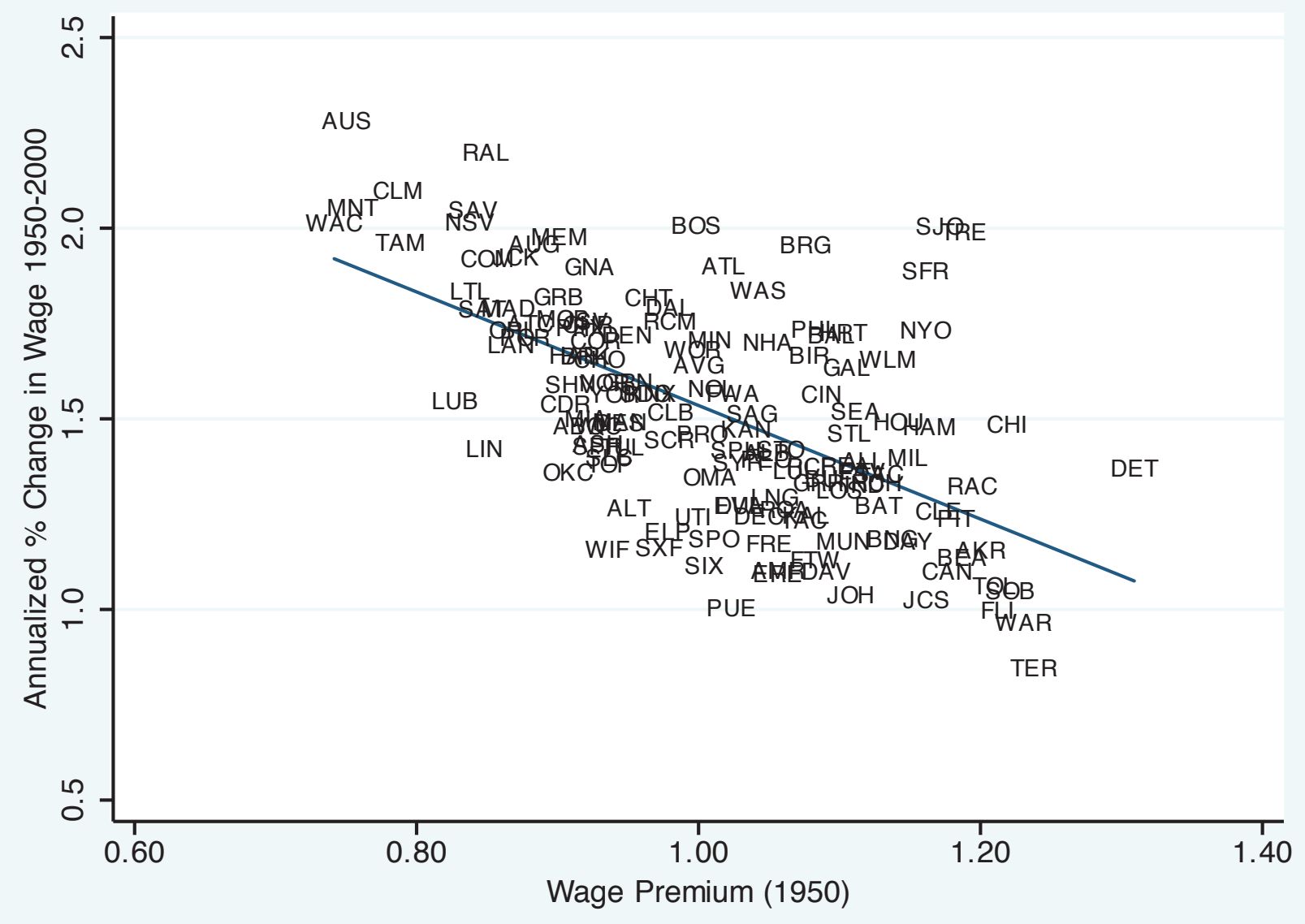

Figure 1: Wage Growth 1950-2000 and Wage Premiums in 1950

\subsection{Do the Wage Premiums Reflect Labor Market Distortions?}

Thus far we have not provided any economic interpretation for the observed wage premiums. A high wage premium could in principle reflect that the regions' workers are simply positively selected on unobserved characteristics that are valuable in production. Instead, we ask whether the premiums reflect a non-competitive labor market, at least for those cities with the highest wage premiums. The interpretation we consider is that non-competitive labor markets lead workers to earn wages in excess of their marginal products.

To answer this question, we re-visit the top 10 MSAs in terms of wage premiums. Table 2 plots the top 10 and their respective premiums. One common theme is that every city on the list is a classic Rust Belt city, with a high manufacturing base and located in the midwest. The range runs from 1.18 in Pittsburgh to 1.30 in Detroit; in all 10 MSAs the size of the premiums are substantial. Also of note is that basically all cities in Table 2 are places where the workforce was heavily unionized in 1950 (see e.g. Goldfield (1987).) Two industries, steel and automobiles, and two 


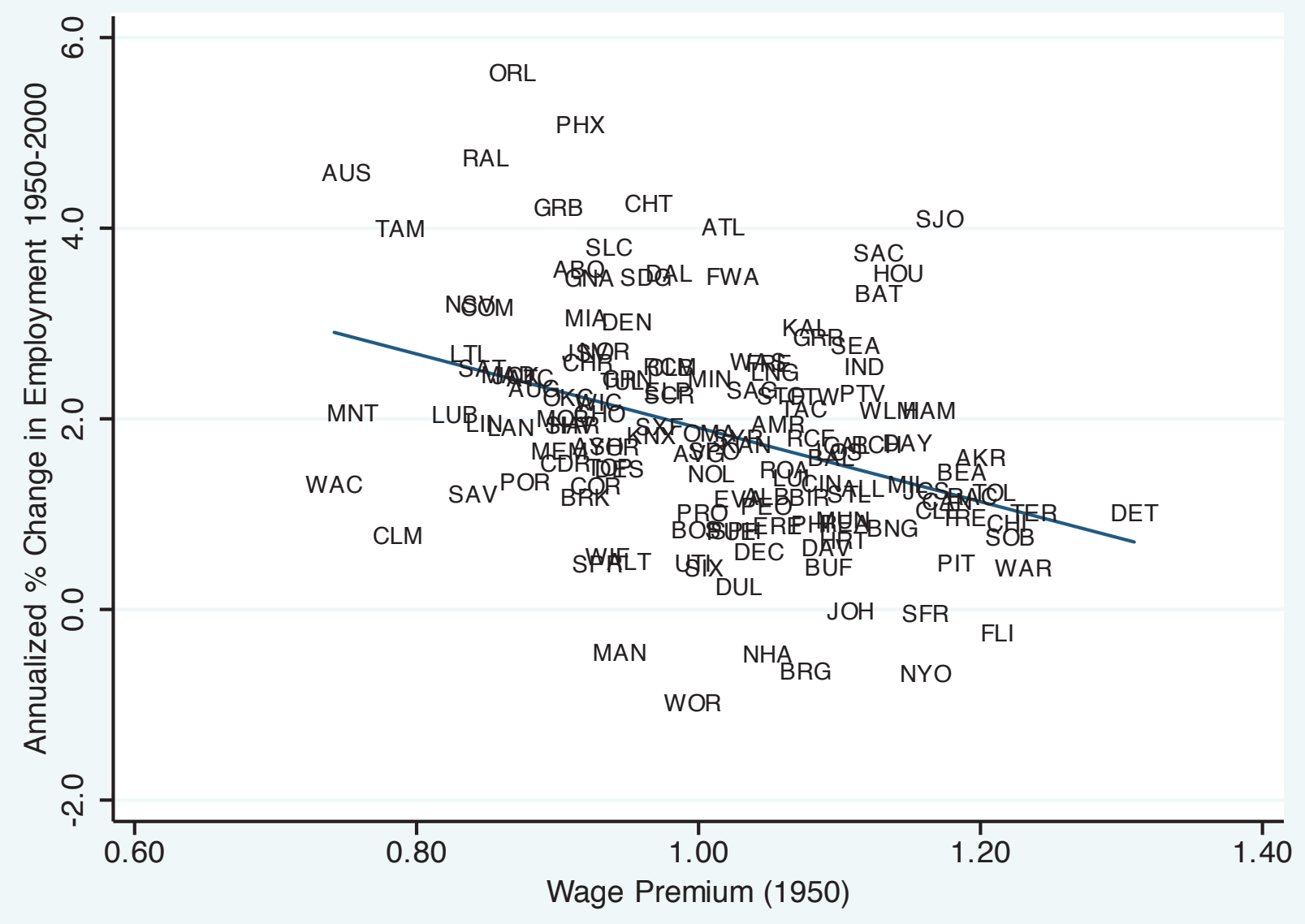

Figure 2: Employment Growth 1950-2000 and Wage Premiums in 1950

unions, the United Steelworkers (USW) and United Auto Workers (UAW), dominated the majority of these cities. The highest concentration of auto workers were Flint and Detroit, with 52\% and $29 \%$ of all workers in these regions employed in automobile manufacturing. South Bend, Toledo and Racine were also major automobile producing regions. As for Steel, $27 \%$ and $17 \%$ of all workers in Youngstown-Warren and Pittsburgh were steel workers, respectively, making these two cities two of the most steel intensive regions in the country in 1950. The Chicago-Gary MSA was also a major Steel center.

Rounding out the list are Akron, $\mathrm{OH}$ and Terre Haute, IN. While these cities were not steel or auto centers, they were still heavy manufacturing centers with highly unionized workforces. Akron was once known as the "Rubber Capital of the World," and many of whose manufacturing workers were organized into the United Rubber Workers union (which later became part of the USW in the 1990s). Terre Haute was a diverse manufacturing center in 1950, with substantial employment in industries such as steel and meat packing, and a powerful union presence, including from the 
Table 2: MSAs with Highest Wage Premiums in 1950

\begin{tabular}{l|c|c}
\hline \hline Rank & MSA Name (ID) & Wage Premium \\
\hline 1 & Detroit, MI (DET) & 1.30 \\
2 & Terre Haute, IN (TER) & 1.24 \\
3 & Youngstown-Warren, OH (WAR) & 1.23 \\
4 & South Bend, IN (SOB) & 1.22 \\
5 & Chicago-Gary, IL (CHI) & 1.21 \\
6 & Flint, MI (FLI) & 1.21 \\
7 & Toledo, OH (TOL) & 1.21 \\
8 & Akron, OH (AKR) & 1.20 \\
9 & Racine, WI (RAC) & 1.19 \\
10 & Pittsburgh, PA (PIT) & 1.18 \\
\hline \hline
\end{tabular}

The wage premium in MSA $i$ is defined as the ratio of wage to skill in $i$ compared to the national average ratio, as in (2), where skill is defined as in (1).

United Auto Workers. ${ }^{6}$

There is ample direct evidence that unions such as the United Steelworkers and United Auto Workers were able to extract large wage premiums for their workers. Ingrassia (2011) documents that the UAW extracted larger and larger wages, benefits and other controls over production from the "Big Three" of Ford, General Motors and Chrysler from WWII through the 1970s. By 1973, a UAW worker could earn "princely sums" working on production or other union-created "jobs," such as serving on the plant "recreation committee," and then retire with full benefits at age $48 .^{7}$

\subsection{Alternative Measures of Wage Premiums: Wage Loss of Displaced Workers}

In future work, we plan to ask whether we get similar measures of wage premiums when looking at the wage loss of displaced workers by region or industry. Previous work, such as that of Carrington and Zaman (1994) or Jacobson and Sullivan (1993) suggests that we will. In that study, the authors find that the largest wage losses after exogenous displacements - such as a plant closing or mass layoff - are in heavy manufacturing industries, such as steel and automobiles.

\footnotetext{
${ }^{6}$ Copious footnotes are forthcoming.

${ }^{7}$ See Ingrassia (2011) pages 46, 56
} 


\subsection{Future Work: Productivity Growth by Industry/Region}

In future work, we also plan to look at productivity growth by industry. We can do this using the NBER CES database, which contains measures of inputs and outputs by industry from 1956-1997.

\subsection{Non-Competitive Behavior in the Rust Belt}

The evidence presented thus far has pointed to non-competitive labor markets in the rust belt region. It is worth noting that there is also evidence that output markets were non-competitive as well. Many of the major industries were characterized by monopoly or oligopoly, and some accounts of Rust Belt industries describe them as tacitly colluding.

Consider first the steel industry. Tiffany (1988) describes the industry as being an oligopoly acting essentially as a single monopolist for much of the postwar period, with U.S. Steel taking the lead in setting prices and the other two large participants matching their prices shortly thereafter. As for autos, Ingrassia (2011) describes the automobile industry as having a "model of corporate oligopoly and labor monopoly" throughout the 1950s, 1960s and 1970s (page 29). In 1958, GM, Ford and Chrysler accounted for $90 \%$ of automobile sales in the United States (page 28.)

This suggests that the non-competitive behavior of Rust Belt industries was not just confined to labor markets. More on this to come.

\section{Simple Model}

Our theory is based on a two-sector open economy version of the neoclassical growth model. We label the two sectors as Sun Belt $(S)$ and Rust Belt $(R)$

\subsection{Preferences}

Households do not value leisure and order their preferences over consumption streams of $Y^{S}$ and $Y^{R}$ denoted by $C^{S}$ and $C^{R}$, respectively:

$$
U\left(\left\{C^{S}\right\}_{t},\left\{C^{R}\right\}_{t}\right)=\sum_{t=0}^{\infty} \beta^{t} U\left(C_{t}^{S}, C_{t}^{R}\right)
$$

The household as a whole sums the valuations of each of its members. Each one of them consumes the per capita amount of the two goods. We implicitly assume that the family household has measure one at all times. As a result, aggregate and average consumption of each good are identical. 
$C^{S}$ and $C^{R}$ are themselves composites of domestic and foreign products. In particular,

$$
\begin{aligned}
& C^{R}=\left(\mu R^{\frac{\rho-1}{\rho}}+(1-\mu) R^{* \frac{\rho-1}{\rho}}\right)^{\frac{\rho}{\rho-1}} \\
& C^{S}=\left(v S^{\frac{\sigma-1}{\sigma}}+(1-v) S^{* \frac{\sigma-1}{\sigma}}\right)^{\frac{\sigma}{\sigma-1}},
\end{aligned}
$$

where $\rho(\sigma)$ denotes the substitution elasticity between domestic and foreign Rust Belt (Sun Belt) consumption goods. $R$ (and $S$ ) are produced domestically while $R^{*}$ (and $S^{*}$ ) are imported from abroad.

\subsection{Technology}

Since households do not value leisure they supply their periodic labor endowment inelastically to the representative firm in each industry. The firms, in turn, have access to a constant returns to scale technology using labor as their sole input:

$$
Y^{R}=A^{R} N^{R} \quad \text { and } \quad Y^{S}=A^{S} N^{S}
$$

where $A^{R}$ and $A^{S}$ denote TFP in the two industries. $N^{R}$ and $N^{S}$ are the corresponding labor inputs. The foreign family household has an analogous taste for variety. It also desires domestic and foreign products. It purchases $H_{X}$ and $L_{X}$ from domestic producers. The resource constraints for light and heavy goods in the domestic economy are:

$$
Y^{R}=R+R_{X} \quad \text { and } \quad Y^{S}=S+S_{X}
$$

Domestic and foreign producers have access to a trading technology of the iceberg variety. To deliver a single unit to a foreign destination, the producer ships $\tau>1$ units. Trading is costly since $\tau-1$ units "melt" in transit.

For simplicity, we assume a two-country world. It consists of the United States and the Rest of the World (ROW) and we model the former as a small open economy for the time being. The iceberg costs between the U.S. and the ROW are symmetric. Without loss of generality we assume that the domestic Sun Belt good is the numeraire.

To fix ideas, let us first consider the closed economy version of our model. In terms of model parameters, this implies $\mu=v=1$. In this case, we can simplify the notation by setting $Y^{R}=$ $C^{R}=R$ and $Y^{S}=C^{S}=S$. 


\subsection{Closed Economy}

The critical difference between the $R$ and $S$ sectors lies in their respective market structure. The production of $S$ is perfectly competitive. Incumbents and entrants have access to the same linear technology $A^{S}$. The incumbent monopolist in $R$, on the other hand, uses the technology $A^{R}$ while potential entrants must rely on an alternative technology with constant marginal cost $\hat{p}^{R}{ }^{8}$ Given that the substitution elasticity between $R$ and $S$ is unity, the price-setting firm has an incentive to minimize output such that prospective entrants are deterred and profits are maximized. ${ }^{9}$

It turns out to be helpful to characterize the solution of the household's problem before we proceed to the firms' problems.

\subsubsection{Household's Problem}

Since production does not require capital, the household's (see below) problem is static. For that reason we drop the time subscript $t$ in equation (3) whenever possible. The household maximizes utility subject to a standard budget constraint.

$$
\begin{aligned}
& \max _{R, S} U(R, S)=R^{\alpha} S^{1-\alpha} \\
& \text { subject to: } \quad w+\pi^{R}\left(N^{R}\right) \geq p^{R} R+p^{S} S
\end{aligned}
$$

where $\pi^{R}$ denotes profits in the Rust Belt industry. We assume that $\pi^{R}$ is rebated lump sum to the workers in the industry. Since $S$ is the numeraire and hence $p^{S}=1$, the problem's first order conditions imply:

$$
p^{R}=\frac{1-\alpha}{\alpha} \frac{S}{R}=\frac{1-\alpha}{\alpha} \frac{A^{S} N^{S}}{A^{R} N^{R}}
$$

\subsubsection{Firms' Problems}

The representative firm in each sector maximizes contemporaneous profits. Since $R$ is not a competitive market, the firm takes the price effect of production decisions into account.

$$
\begin{aligned}
& \max _{N^{S}} \pi^{S}=A^{S} N^{S}-w N^{S} \\
& \max _{N^{R}} \pi^{R}=p^{R}\left(N^{R}\right) A^{R} N^{R}-w N^{R}
\end{aligned}
$$

\footnotetext{
${ }^{8}$ One can think of the incumbent as a representative monopolist in an environment where individual firms perfectly coordinate their production decisions.

${ }^{9}$ In future work, we expect to generalize the non-competitive market structure with more than one Cournot competitor and a competitive fringe. The qualitative results are not sensitive to this alternative specification.
} 
The first order condition (with complementary slackness) for the price-setting producers in $R$ is:

$$
\begin{aligned}
& \frac{\partial \pi^{R}}{\partial N^{R}}=\frac{\partial p^{R}}{\partial N^{R}} A^{R} N^{R}+p^{R} A^{R}-w \leq 0 \\
& \text { where } \quad \frac{\partial p^{R}}{\partial N^{R}}=\frac{\partial p^{R}}{\partial A^{R} N^{R}} \frac{\partial A^{R} N^{R}}{\partial N^{R}}=\frac{\partial p^{R}}{\partial R} A^{R} \quad \text { and } \quad \frac{\partial p^{R}}{\partial R}=-\frac{1-\alpha}{\alpha} \frac{S}{R^{2}}
\end{aligned}
$$

It follows that

$$
A^{R}\left(p^{R}-\frac{1-\alpha}{\alpha} \frac{S}{R}\right) \leq w
$$

Since the substitution elasticity is unity, the profit-maximizing output is zero in the limit and the firm's first order condition holds with strict inequality. However, since there is a competitive fringe of prospective entrants who have access to an alternative technology with constant marginal cost $\hat{p}^{R}$, incumbents produce just enough output to deter entry. That is, industry employment is such that:

$$
\hat{p}^{R} \geq \frac{1-\alpha}{\alpha} \frac{A^{S}}{A^{R}} \frac{N^{S}}{N^{R}}=\frac{1-\alpha}{\alpha} \frac{A^{S}}{A^{R}} \frac{N-N^{R}}{N^{R}}
$$

Solving for employment in $R$ yields:

$$
N^{R *} \geq \frac{N(1-\alpha) A^{S}}{\alpha A^{R}}\left(\hat{p}^{R}+\frac{(1-\alpha) A^{S}}{\alpha A^{R}}\right)^{-1}
$$

The profits are the difference between marginal cost and marginal revenue multiplied by the measure of workers in $R$ :

$$
\pi^{R *}=N^{R *}\left(\hat{p}^{R} A^{R}-w\right)
$$

Our model is silent on the distribution of these profits and we assume that they are rebated lumpsum to the workers in the industry. ${ }^{10}$ The measure of labor market rents that matches our empirical measure of the wage premium for the Rust Belt region is

$$
P^{R}=\frac{w+\frac{\pi^{R *}}{N^{R *}}}{w}
$$

\subsection{Open Economy}

When we set $\mu, v \in(0,1)$, households have preferences over four different consumption streams: domestic and foreign varieties of both $S$ and $R$. Imported Sun Belt (Rust Belt) goods are denoted by $S^{*}\left(R^{*}\right)$. Similarly, the prices for imported goods are denoted by $p^{S *}\left(p^{R *}\right)$.

\footnotetext{
${ }^{10}$ In future work, we expect to model the bargaining process explicitly.
} 
Households solve

$$
\begin{aligned}
& \max _{C^{R}, C^{S}} U(R, S)=\left(C^{R}\right)^{\alpha}\left(C^{S}\right)^{1-\alpha} \\
& \text { subject to: } \quad w+\pi^{R}\left(N^{R}\right) \geq p^{R} R+p^{S} S+p^{S *} S^{*}+p^{R *} R^{*},
\end{aligned}
$$

where $C^{R}$ and $C^{S}$ are given by (4) and (5).

In addition, we impose the following balanced trade condition:

$$
p^{S} S_{X}+p^{R} R_{X}=p^{S *} S^{*}+p^{R *} R^{*}
$$

Since our empirics focus on the United States, we do not explicitly model the rest of the world and instead take the prices of imported goods as given. As far as the non-competitive producers are concerned, they are no longer concerned exclusively with a domestic competitive fringe. Instead, they worry about being displaced by foreign producers of similar goods. The profit maximizing output level is a function of $p^{R *}$ and the substitution elasticity $\rho$.

\subsection{Equilibrium}

In addition to the optimality conditions, the equilibrium requires market clearing for labor $(1=$ $N^{R}+N^{S}$ ) and balanced trade as in (14).

Definition 1 (Equilibrium) An equilibrium consists of prices $w, p^{R}, p^{R *}$, and $p^{S *}$; labor inputs $N^{R}$ and $N^{S}$ and hence output quantities $Y^{R}$ and $Y^{S}$; allocations of $S, R, S^{*}$, and $R^{*}$ such that, given these prices,

- households maximize lifetime utility subject to the budget constraint,

- firms maximize profits,

- market for labor clears; and

- international trade is balanced. 


\section{References}

Bils, M., And P. J. Klenow (2000): "Does Schooling Cause Growth?,” American Economic Review, 90(5), 1160-83.

Blanchard, O., And L. Katz (1992): “Regional Evolutions,” Brookings Papers on Economic Activity, 1992(1).

Bridgman, B. (2011): “Competition, Work Rules and Productivity,” Unpublished Manuscript, Bureau of Economic Analysis.

CARrington, W., And A. Zaman (1994): "Interindustry Variation in the Costs of Job Displacement," Journal of Labor Economics, 12(2), 243-275.

GoldFIELD, M. (1987): The Decline of Organized Labor in the United States. The University of Chicago Press, Chicago.

Herrendorf, B., And A. TEIXEIRA (2012): “Barriers to Entry and Development," International Economic Review.

Holmes, T. J., And J. A. Schmitz (2010): "Competition and Productivity: A Review of Evidence," Annual Review of Economics, 2, 619-642.

IngrassiA, P. (2011): Crash Course. Random House, New York.

Jacobson, Louis S., R. J. L., And D. G. Sullivan (1993): “Earnings Losses of Displaced Workers," The American Economic Review, 83(4), 685-709.

Parente, S. L., And E. C. Prescott (1999): "Monopoly Rights: A Barrier to Riches," American Economic Review, 89(5), 1216-1233.

Ruggles, S. J., T. Alexander, K. Genadek, R. Goeken, M. Schroeder, and M. Sobek (2010): “Integrated Public Use Microdata Series: Version 5.0," [Machine-readable database]. Minneapolis: University of Minnesota.

Schmitz, J. A. (2005): "What Determines Productivity? Lessons from the Dramatic Recovery of theU.S. and Canadian Iron Ore Industries Following Their Early 1980s Crisis," Journal of Political Economy, 113(3), 582-625.

Tiffany, P. A. (1988): The Decline of American Steel. Oxford University Press. 